\title{
Security of Insurers: The American Risk Based Capital Model versus the European Model of Solvability for Property and Casualty Insurers
}

\author{
by Dieter Farny*
}

\section{Background}

The long term security of existence of insurers, expressed as the preservation of the undertaking, its capital, liquidity and future potential success and, just as importantly, the avoidance of crises, are the key goals of both the insurer itself and also the proprietors and the policyholders. Furthermore, the avoidance of crises and financial ruin is high on the priority list of the supervisory authorities in all countries with an insurance industry. Thus far there is broad international consensus.

On the other hand there is a general lack of consistency between the different models used to demonstrate this problem of security or preservation, as well as between the methods used by both the undertakings and the supervisory authorities to deal with it.

From the point of view of the individual insurance undertaking, security policy belongs to the wider area of its own risk management. In practical terms, the question posed is this: how can an insurer measure and control his own risk and security position, and what instruments are available to bring to bear on that security position. One of the most important instruments here is the availability of security capital (capital and reserves).

A similar question arises from the point of view of state supervision: how can a supervisory authority measure and control the risk and security position of the insurance undertaking to be supervised and which supervisory instruments are available to guarantee a minimum standard of security for the individual insurer concerned? This minimum standard should safeguard insurers from financial crises, allow them to fulfil their obligations at all times and in the long term, and above all prevent them from ever going into liquidation.

The long term security of existence of insurers, in particular their claims paying ability is also an important factor in the general evaluation of the quality of insurers by rating systems.

The US National Association of Insurance Commissioners (NAIC) has been developing the Risk Based Capital (RBC) model since the end of the 1980's and introduced its application to life and health insurers as well as property and casualty insurers at the beginning of the 1990's. The major American rating agency A.M. Best has recently presented a Capital Adequacy model that is used in the context of the rating process.

\footnotetext{
* Director of the Institute of Insurance Science, Cologne University.
} 
The basic idea of the RBC model corresponds to the European solvability model. The latter was incorporated in the national supervisory systems by means of the First and Second EC Directives. Many years' experience are now available and it is therefore interesting to compare the American RBC model with the European solvability model and to investigate whether any suggestions for improvements can be derived therefrom. Such an investigation is of interest both in relation to the supervisory solvability system and to the corporate security policy of individual insurers.

\section{The concepts}

The security of an insurer's existence - that can be positively expressed as the probability of its survival or negatively as the probability of its financial ruin, viewed both in the short and long term - can generally speaking be demonstrated by two measures:

(1) The total risk position of an insurance undertaking which results from the effects of all the individual risk components, the latter particularly in the areas of premiums, claims, composition of the portfolio, outwards reinsurance and capital. The probability distribution of profits or losses arising from the totality of the insurer's activities, and in particular the probability distribution of the loss situations, are of central importance in the expression of the total risk position.

(2) The amount of security capital or capital and reserves necessary to cover emerging losses and thus to "survive" a loss situation.

The American RBC model and the European solvability model are constructed from these basic premises. Both systems encompass four principal criteria:

(1) How is the risk position measured by the insurers?

(2) What security capital or capital and reserves requirement is deduced from this measurement of the risk position, what should the size of the security capital or capital and reserves requirement be having regard to the totality of the undertaking's activities?

(3) What is the amount of security capital or capital and reserves actually available?

(4) What supervisory consequences are foreseen in the event of the existing capital amount falling short of the required capital amount?

It must again be stressed that these four criteria not only determine the supervisory security concept but are also of significance for the security policy of the individual undertaking concerned.

The American RBC model and the European solvability system differ most markedly in respect of the first criterion, namely the modelling and the quantitative measurement of the risk position of insurers. It is here that differences clearly arise, resulting from different accounting principles for drawing up the end-of-year accounts, as well as differing product and premium concepts. This is an expression of the different "cultures" of the national insurance markets, the insurance business transacted and the accounting principles. There are considerable differences between U.S.A. and Europe, though the national cultures in Europe have by no means yet been smoothed out by the internal insurance market of the EU. 


\section{The basic problems}

A number of important individual problems have arisen out to the long history of corporate and supervisory security policy (solvency control, financial supervision) that to date have only been resolved to a limited extent.

(1) A compromise must be found in all models between objective correctness and functionality. Objectively correct solutions, that are commensurate with reality in terms of structure and process, are usually very complex and therefore less functional. Functional solutions on the other hand mostly only have a limited degree of objective correctncss because they are insufficiently differentiated. This dilemma has been solved in different ways by the American RBC model and the European solvability model: the RBC model seeks greater objective correctness by means of a high degree of differentiation, the European model places a strong emphasis on functionality.

(2) The models operate with different data inputs. Information is derived from the published annual accounts or additionally from internal reports made by the insurers to the supervisory authority. Rating systems frequently use other sources of data as well. Considerable problems arise from the comparison of data from annual accounts if these are based on different accounting principles. The basis of the data is also of great significance when establishing standards, norms and benchmarks against which the individual corporate situation is assessed.

(3) Furthermore the question must be resolved whether the risk positions of the insurance undertakings are to be measured using historical or current information, or whether predictions of future developments should be used as well. This also affects the necessary differentiation of models for property and casualty insurances (that tend to be short term) and life and health insurances (that tend to be long term). In property and casualty insurance, the individual transactions tend to be short term, the risk positions of the insurers are very volatile, insurance business crises can however be relatively quickly overcome due to more easily alterable terms and conditions. Longer term risk problems relate above all to insufficient claims reserves for long-tail claims and IBNR claims. A very different situation exists for life insurance and (European) health insurance. Here it is not so much the current risk position of the insurer that counts, but rather the potential risks for the remaining duration of the policies, a time span that can extend to 30-50 years with the type of products normally found in Europe. Here the sccurity of the insurance undertaking not only affects the settlement of claims that have already occurred and potential losses arising during the remaining periods of insurance, but also the saving process and the undisturbed continuation of the policies, something of considerable importance to the policyholders above all.

(4) Currently the question is being asked whether the risk or security position of an individual insurance undertaking is still the correct approach at all if that undertaking belongs to a large insurance group or a financial conglomerate consisting of banks and other financial institutions in addition to insurers. In such cases, the individual insurer's fate in terms of risk may also be determined by the fate of other undertakings in the group and by the business relationships between the individual members of the group. In this instance, the risk and security models must then take into consideration both external influences on the undertaking arising from the group or conglomerate as well as positive or negative correlations of the risk positions of the individual undertakings. 


\section{The RBC model from a European point of view}

The US RBC model of NAIC for property and casualty insurers cannot be described in detail here. The following aspects are of particular significance for its evaluation from a European point of view:

(1) The overall risk position of an insurance undertaking is divided by the RBC model into partial positions, namely the following:

- The underwriting risk is defined in different ways, i.e. as based on an appropriate premium calculation reflected in the claims ratios and underwriting results, as well as on the adequacy of the claims reserves for incurred losses. The underwriting risk of the individual classes of business is weighted according to experience and expectation of fluctuations.

- The asset risk is subdivided by type of investment, whilst taking the assets within the group into account.

- The credit risk in respect of existing and potential debtors is determined with particular reference to claims against reinsurers.

- Off balance sheet risks, e.g. relating to guarantees for other undertakings in the group and the risks arising from excessive growth are also taken into account: the latter is an extremely interesting aspect for European considerations.

(2) The interacting relationships between the partial risks assessed (positive and negative correlations, covariances) are taken into consideration, although the mathematical techniques used are not very sophisticated.

(3) By aggregating the partial risks after covariance adjustment or by aggregating the security capital amounts deemed necessary in this respect, the total amount of security capital is calculated (Total Risk Based Capital after Covariance).

(4) This required amount is compared to the security capital actually available (Total Adjusted Capital), the risk position is deemed critical if the actual amount is less than the required amount.

It is difficult to reach a general conclusion when comparing the RBC model for property and casualty insurers with the European solvability model. Both systems consist of a significant mixture of advantageous and disadvantageous characteristics, both from the point of view of insurance supervision and in terms of the risk strategies of insurers from which the following points emerge.

(1) The RBC model tries to assess the complex overall business risk position of insurers in a more differentiated manner than the European solvability model. This applies above all to the differentiation between the risks arising out of the insurance business and those arising out of the investment business; in Europe such an approach is only required for life insurance. On the other hand, in the RBC model the connections between the insurance and the investment business are not distinguished in a clear manner. Above all, fluctuations in the insurance business and the investment business have completely different causes and also often depend on the circumstances involved. In property and casualty insurance it is not only the quality of the investments that is important but also the amounts in relation to the insurance business volume having regard to the potential for interest earnings and capital gains from the investments (cash flow underwriting). In the RBC model such factual information is only shown in an inexact 
manner, thus impairing its suitability for the supervisory control of insurers. Overall however the RBC model provides significantly better indicators for the corporate risk strategy of the insurers themselves, because it is concerned with the individual variables of the risk position and the risk strategy instruments. In other words the model does not solely depict highly aggregated amounts from the outset.

(2) The RBC model does not clearly distinguish risks relating to current operations and risks relating to assets and capital positions. The business approach demonstrates three portfolios for each insurer:

- the insurance portfolio with current flows of premiums, claims, expenses and reinsurance,

- the investment portfolio with changes in value, earnings and expenditure,

- the portfolio of liabilities arising out of insurance business, in particular the claims reserves and also the actuarial reserves in respect of life and health insurance.

Each of the three portfolios has its own risk profile, and the art of the business strategy can be described as the management of these three portfolios with the aim of an optimum target size combining the undertaking's security and profitability. To that extent integrated risk strategies are perfectly valid, yet the $\mathrm{RBC}$ model takes disaggregated strategies as its starting point, only combining them again at the very end of the process by means of very generalised methods.

(3) An old problem of the security policy for insurance undertakings is the setting of standards for adequate security funds. In the European solvability system fixed amounts are specified as minimum solvency requirements whereas the RBC model operates to a greater extent on the basis of standards derived from long term average values of the classes of insurance. This is certainly a good solution as it adjusts itself to changes in circumstances. However the quality of such benchmarks stands and falls by their determination. In particular, general averages for a whole class of business are not very suitable if the business of individual insurers, and thus their risk situation, is not the average for that class but distinct from it. The effect of very large insurers on the class average also often distorts the benchmarks. Finally the class averages always relate to the past and do not take the future into consideration. Nevertheless one can conclude that empirically based, flexible standards are more appropriate than fixed norms, particularly if the origin of the latter is unclear and they are not adjusted to continual developments.

(4) The differentiated evaluation of investment risks by the RBC model is a positive advantage, as is the distinction between investments inside and outside the group and the special cumulative risks of individual investees. The marked differentiation of the calculations does however often create the false impression of an exactness that does not exist in reality. The covariances between the individual categories of investment are not, or hardly, taken into account, despite their significance having regard to the connections between the individual sectors of the investment and property markets. Doubts also arise whether the situation of the American investment markets can be applied to the European markets without distinction. It should also be noted that in many European countries the investment risks are limited by stricter investment regulations. 
(5) The effects of outwards reinsurance on risk strategy are not strongly recognised in the $\mathrm{RBC}$ model. This is a considerable disadvantage for property and casualty insurance. The underwriting risk is based on the total net insurance business and therefore depends considerably on the adequacy, from the risk strategy point of view, of the types and extent of reinsurance protection acquired, above all on the mixture of proportional and non-proportional reinsurance or arrangements characterised by the use of financial reinsurance instruments. These effects are neither given their due importance by the $\mathrm{RBC}$ model nor by the European solvability calculations, so that the potential for errors does exist here. Although the separate evaluation in the RBC model of the quality of amounts due from reinsurers is appropriate from a technical point of view, it receives too much weight having regard to the primary problem of the reinsurance arrangements.

\section{Some conclusions}

The assessment and control of risk situations and risk strategy instruments of insurers is a fundamental duty of both individual insurers themselves and the supervisory authorities. Each new model for risk control is therefore a welcome innovation and their contributions to improving systems must be examined carefully. This also applies to a comparison of the European solvability system and the American RBC model.

An initial, and superficial, comparative evaluation produces the following conclusion.

The European solvability system is comparatively crude, its theoretical foundations weak, but its aplication is very straightforward. The dilemma between objective correctness and functionality is resolved in favour of the latter.

The American RBC model is significantly more differentiated, although its theoretical foundations are also weak; it is harder to apply in practice. In the dilemma between objective correctness and functionality, the former principle is considered significantly more important. Noticeable efforts have been made to encompass the real structures of the risk problems of insurers. This has been successfully done on a formal level; but whether the same material structural equivalence of the risk problem between reality and the RBC model can also be achieved will only be known after extensive tests or after several years of practical experience. At present doubts still exist on the levels of risk theory and business operations whether the reality has really been accurately portrayed.

Of particular interest in the appraisal of the European solvability system is the replacement of prescribed safety standards by a system of norms that have been derived from reality in a flexible way. However this conclusion only applies to the concept of using benchmarking in this connection. The American benchmarks themselves cannot be applied to the European insurance markets whose characteristics are completely different.

This is particularly the case with life and health insurance business, which in Europe and in individual European countries differs significantly from the situation in America. By contrast the differences found in property and casualty insurance are much less marked. In so far as the comparison of safety capital requirements is concerned, the different regulatory systems of the national markets must also be taken into account. Above all this concerns the very different interests that policyholders and proprietors of undertakings 
(shareholders) have in the security of insurance undertakings. Besides, working with fixed legal norms corresponds more closely to (continental) European legislative culture than adherence to flexible standards; the latter are also hardly subject to legal process.

In so far as the RBC model serves supervisory safety controls, a certain scepticism is justified as to whether it could be transferred to Europe. Such a move would in any case entail legal and practical problems as it would require action by the European legislature, the results of which would then have to be incorporated into national legislation. Consideration would also have to be given to the fact that European insurance markets are (still) highly diversified in comparison to the American market.

The contribution of the RBC model to the individual insurers' own risk strategies is much more positive, as these are not primarily pursued for the supervisory authorities but in order to attain self-determined security goals. The risk strategy of insurers was and is relatively undifferentiated. Here the RBC model can provide ideas by disclosing individual risk and safety problems, so that the assessment, evaluation and organization of the overall risk situation does not first take place at a high level of aggregation but is built "from the bottom up". From this point of view the RBC model provides good starting points and many practical indicators. The European insurers will therefore study the RBC model not so much because it might one day become the supervisory solvability model of the European insurance supervision authorities but rather to improve the quality of their own business policy in so far as security is concerned.

\section{REFERENCES}

\section{List of more recent German literature}

FARNY, Dieter: Versicherungsbetriebslehre, 2nd Edition, Karlsruhe, 1995, pp. 445-461, 678-697.

MULLER, Eberhard: Risk-Based-Capital für Versicherungsunternehmen: Der amerikanische Ansatz, in: Zeitschrift für Versicherungswesen, (46) 1995, pp. 586-592.

MÜLLER, Eberhard; REISCHEL, Michael: Vom theoretischen Konzept des Risikoreserveprozesses zur praktischen Messung und Steuerung des Risikokapital (Risk-Based-Capital), in: Hesberg, Dieter; Nell, Martin; Schott, Winfried (Publ.): Risiko, Versicherung, Markt, Festschrift for Walter Karten, Karlsruhe, 1994, pp. 465-500. (English translation in The Geneva Papers on Risk and Insurance, No. 78, January 1996).

HESBERG, Dieter: Solvabilität als Gegenstand der Risikopolitik, in Zeitschrift für die gesamte Versicherungswissenschaft, (72) 1983, pp. 255-284.

SCHRADIN, Heinrich R.: Erfolgsorientiertes Versicherungsmanagement - Betriebwirtschaftliche Steuerungskonzepte auf risikotheoretischer Grundlage, Karlsruhe, 1994.

SCHRADIN, Heinrich R.; TELSCHOW, Ingo: Solvabilitätskontrolle in der Schadenversicherung eine betriebswirtschaftliche Analyse der Risk Based Capital - Anforderungen in den Vereinigten Staaten, in: Zeitschrift für die gesamte Versicherungswissenschaft, (84) 1995, pp. 363-406.

Schweizerische Rückversicherungs-Gesellschaft (Publ.): Insolvenzentwicklung und Bedeutung der Bonität in der Assekuranz, sigma 1995, No. 7, Zurich, 1995 (also available in English).

WAGNER, Fred: Solvabilitätspolitik als Unternehmenspolitik von Kompositversicherungsunternehmen, Berlin, 1992. 